\title{
Genitive constructions in Coptic
}

\author{
Barbara Egedi
}

\section{Introduction}

\subsection{Definition of 'Coptic'}

Coptic is the language of Christian Egypt $\left(4^{\text {th }}\right.$ to $14^{\text {th }}$ century) written in a specific version of the Greek alphabet. It was gradually superseded by Arabic from the ninth century onward, but it survived to the present time as the liturgical language of the Christian church of Egypt. In this paper I examine only one of its main dialects, the Sahidic Coptic and I use a transcription which simply reflects the Coptic letters irrespectively of phonological details. $^{1}$

\section{2. $U G$ in the reconstruction of dead languages}

Natural languages are claimed to have universal properties or principles which constitute what is referred to as Universal Grammar. Accepting certain universal principles and observing the corresponding parameters in Coptic, we can also analyse a language without living native speakers, and explain its structural relations with the help of coherent models.

For example, it is considered a universal principle that the projections of lexical heads are extended by one or more functional projections. If we assume that it can be demonstrated in many languages, why could not we suppose the same in the case of Coptic? Indeed, as it will be shown in chapter 4 , there are at least two functional projections above Coptic lexical noun phrase as well.

The aim of this paper is to provide an adequate account of the basic structure of the Coptic NP within the theoretical framework of the Minimalist Program (a short summary of which will be found in the following section); at the same time, I intend to find the answer to unsolved questions related to genitive constructions. In fact, in many cases even the appropriate questions have not been posed yet. Coptic has two different genitive con- 
structions: one with simple definite possessions and one for indefinite, modified or deictically marked head nouns. After establishing the distribution and the use of the two genitive constructions, I will point out the differences between their internal structures.

The paper is organised as follows: section 2 expounds the theoretical assumptions regarding the noun phrase research and the minimalist program; section 3 examines the Coptic data, the distributional conditions of noun phrases and the internal structure of the two genitive constructions with particular attention to the nature of linking elements between the possession and the possessor. In the last section, I analyse the derivation of simple NPs and that of genitive constructions in the framework of a modified checking theory.

\section{Theoretical background}

\subsection{Layered Noun Phrase}

The research of the noun phrase does not have as old a tradition in generative theories as the research of the verbal constructions and the sentence as a whole. (On the history of this research see Giorgi-Longobardi 1991.) However, since the end of the eighties several suggestions have appeared for an analysis of noun phrases similar to that of sentences, supposing functional categories (whose role is essentially grammatical) above lexical nouns and their phrases. In other words, the noun phrase is actually a DP projected from a Det(erminer), whose complement is an NP. The DP hypothesis traditionally has been ascribed to Abney (1987) but the comparison of NPs with VPs can be traced back to Chomsky's earlier works. ${ }^{2}$

Once this analysis was widely accepted, functional heads appeared in a greater number in the noun phrase corresponding to the multiplied number of functional projections in the clause. Bernstein (1991), Ritter (1991) and others suggested that this functional FP between the lexical NP and the functional DP should be a NumP, a projection responsible for number specifications, and this view is going to be adopted in this paper as well.

The main motivation for supposing an intermediate FP was the requirement to explain the word order variations within the noun phrase across languages and to provide a landing site for N-movement. As the approach presented here intends to be a minimalist one, the notion of movement needs a more accurately formulated motivation ${ }^{3}$ in terms of checking theory. In 
the next section I give a short summary of the principles and methodology of the minimalist program.

\subsection{The minimalist theory}

Chomsky's minimalist theory claims that the syntax (the computational system of Human Language) is a minimally complex system, which maps a numeration of elements from the lexicon to a pair of interface representations at PF and LF, respectively. Syntactic derivation consists of two operations: Merge and Move. Through Merge, uninterpretable features like case and agreement can also get into the syntax. Unlike interpretable elements, uninterpretable features must be erased by LF to satisfy Full Interpretation. In order to be erased, these features must be checked, that is, paired with a corresponding feature in an appropriate structural relation (specifier-head relation, adjoined heads).

The other operation is Move, which applies exactly in order to create this local checking relation: a certain functional category with uninterpretable features attracts the features of a "lower" category. Movement can be visible, in that case it has to take place before Spell-Out in overt syntax, or it can happen covertly, not affecting phonological representation (Chomsky 1993, 1995; Lasnik 1999).

Minimalist feature checking was developed first of all to account for sentence-level agreement, but it can be extended to the NP as well, since concord inside a noun phrase is actually a type of agreement among the $\phi$ features (number, gender, case) of the noun and the determiners and adjectives modifying it. Carstens (2000) provides a detailed account of minimalist analysis to concord - slightly modifying the original theory of movement - , and I rely on her study in many respects. ${ }^{4}$

\section{The Coptic NP}

\subsection{Noun phrases}

Traditional grammars (e. g., Till 1986: §§44-122; Lambdin 1986: passim; Vergote 1950) confine themselves to list exhaustively the possible orders of constituents, the types of articles and other determiners, without trying to explain the relationship between certain phenomena or establishing the 
basic phrase structure of the NP. Two exceptions to this generalisation are Shisha-Halevy $(1986, \S 5.1 .1$. and passim) - however, his view is entirely different from my own - and Layton (2000), who is concerned with article phrases and specifier phrases. ${ }^{5}$

According to the DP hypothesis, argument noun phrases are DPs, maximal projections of the functional category $\mathrm{D}$ (determiner). What is more, the complement of the $\mathrm{D}$ is another functional category, an intermediate projection, often associated with the number specification of the lexical NP. However, only necessary functional projections must be built (Grimshaw 1991).

This supposition of different NP types (NPs, NumPs, DPs) is not an arbitrary classification, it is also motivated by the syntactic distribution of noun phrases: the various noun phrase projections distribute differently across sentence positions (É. Kiss 2000: 124) as the evidence in 3.2.2 will show it.

\subsection{The Coptic data}

\subsubsection{Gender and number}

Nouns have masculine or feminine grammatical gender, but in lack of any modifying element, this feature is usually not expressed morphologically. The formal marking of gender is limited to a class of exceptional nouns which have two related forms corresponding to male and female biological sex $($ son/sōne $=$ brother/sister). In most cases it is the article or some other determiner that shows the gender and also the number specification:

(1) rōme

man

(2) p-rōme def:sg.m.-man 'the man'

(3) pei-rōme dem:sg.m.-man 'this man'

(4) pef-rōme poss:sg.m-man 'his man' sōše

field

$t$-sōše

def:sg.f.-field

'the field'

tei-sōše,

dem:sg.f.-field

'this field'

tef-sōše

poss:sg.f.-field

'his field'
${ }^{e}$ n-rōme/sōše def:pl.-man/field 'the men/fields' nei-rōme/sōše dem:pl.-man/field 'these men/fields' nef-rōme/sōše poss:pl.-men/field 'his men/fields'

hen-rōme/sōše indef:pl.-man/field 'men/fields' 
The definite article and the demonstrative have three distinct forms: in the singular there is a masculine as well as a feminine form, while in the plural no such morphological distinction can be found. The indefinite article has a singular and a plural variant. The possessive article does not only mark the number and gender of the possessed noun like the article but also the person, the number and - in 2. and 3. sg. - the gender of the possessor. ${ }^{6}$

\subsubsection{Distribution}

The distribution of definite and indefinite noun phrases is clearly different in three (morpho)-syntactic cases:

a.) in the so-called 'first present' type sentences, the subject cannot be indefinite, more precisely, an indefinite subject must be preceded by an existential particle:

(6) p-rōme rime def:sg.m-man cry 'the man is crying'

(7a) *ou-rōme rime indef:sg-man cry 'a man is crying'

(7b) oun ou-rōme rime

ex.prt. indef:sg.m-man cry

'a man is crying/there is a man crying'

b.) indefinite noun phrases cannot be modified by the relative converters ${ }^{7}$ et-/ent-, but by the circumstantial converters only. In other words, if the antecedent of a relative clause is indefinite, a circumstantial verbal form follows:

(8) p-rōme et-rime

def:sg.m-man conv:rel.ps- $\varnothing$-cry

'the man who is crying'

(9) ou-rōme e-f-rime

indef:sg-man conv:circ-proN:3sg.m.-cry

'a man who is crying'

c.) Coptic has two types of genitive constructions, in one of which definiteness is obligatory. In fact, the situation is more complicated, since in this pattern the possessed noun must have a definite article but cannot have any other determiner or modifier. 


\subsubsection{Genitive constructions}

Let us call the two genitive constructions pattern A and pattern B, exemplified in (10)-(13):

\section{Pattern A}

(10) $p$-šēre ${ }^{e} m$-p-rōme

def:sg.m-son of-def:sg.m-man

'the man's son'

\section{Pattern B}

(11) ou-šēe ${ }^{e}$ nte-p-rōme

indef:sg-son of-def:sg.m-man 'a son of the man'

(12) $p$-šêre ${ }^{e} n$-sabe ${ }^{e}$ nte-p-rōme

def:sg.m-son adj.prt.-clever of-def:sg.m-man

'the clever son of the man'

(13) pei-šêre ${ }^{e}$ nte-p-rōme

dem:sg.m-son of-def:sg.m-man

'this son of the man'

In both patterns the order of the constituents is: Possessed NP + morpheme expressing genitive relationship, genitive marker + Possessor NP.

The difference between the two constructions is that in pattern A the possessed NP is introduced by a definite article, and the possessor expression is marked by a genitive marker ${ }^{e} n-\left({ }^{e} m-\right),{ }^{8}$ while in pattern $\mathrm{B}$, the possessed NP may be indefinite, preceded by a demonstrative, ${ }^{9}$ or modified by an adjective, and the possessor expression is introduced by a preposition ${ }^{e} n t e-,{ }^{e} n t a-.{ }^{10}$

Before turning to structural investigation, we have to say a few words about the status and nature of these morphemes marking the possessive expression, and about other controversial aspects present also in traditional Coptic grammars.

It is clear that contrary to certain opinions (Lambdin 1986: 6), the ${ }^{e} n-$ element in pattern $\mathrm{A}$ is not a preposition. It has no prepronominal form (as it is expected from a standard preposition). In fact, pronominal possessors are expressed by what we call the possessive article:
(14a) pef-šère poss.art -son
(14b) nef-šère poss.art -son 'his sons'
(14c) tek-maay poss.art -mother 'your mother'


It is somewhat embarrassing that apparently numerous function words have the same form. For example an ${ }^{e} n$ - introduces the direct object ${ }^{11}$ as well, and there is also a partitive preposition ${ }^{e} n$ - illustrated in (15), which is a real preposition with two forms. One has to distinguish it from the genitive marker in (16) functioning more like a case marker morpheme:

(15a) oua ${ }^{e}$ n-nen-eiote one of(part)-our-fathers 'one of our fathers'

(16a) p-nobe ${ }^{e} n$-nen-eiote def:sg.m-sin of(poss)-our fathers 'our father's sin' (15b) oua ${ }^{e}$ mmo-ou

one of(part)-them

'one of them'

(16b) *p-nobe ${ }^{e}$ mmo-ou (16c) peu-nobe def:sg.m-sin of-them poss.art-sin $*$ the sin of them 'their sin'

An ${ }^{e} n$-morpheme introduces adjectives, too, as it can be seen in (12): $p$-šerre ${ }^{e} n$-sabe 'the clever son'. This ${ }^{e} n$ - obviously lacks prepronominal form, too. Observe the following phrases, ${ }^{12}$ the first of which is a genitive, while the second and the third are attributive constructions:

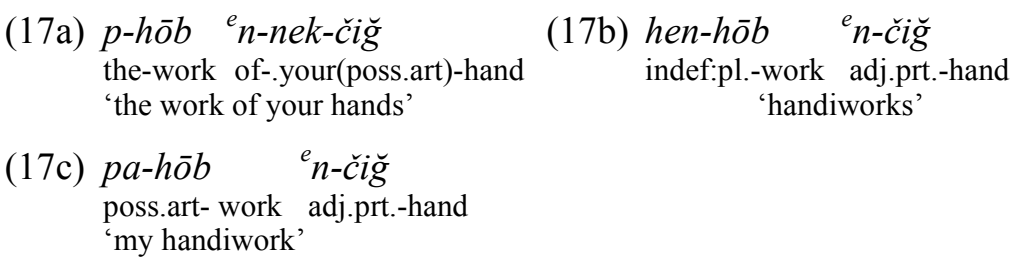

What is it that shows us that the ${ }^{e} n$ - in (17b) is not a genitive marker? First, bare nouns have a very restricted use in Coptic, some kind of an article usually appears with them. Adjectives, on the other hand, do not need any article or determiner, apart from this linking element. ${ }^{13}$ Loprieno considers it a determinative pronoun comparing it with that in Hebrew attributive constructions (Loprieno 1995: 56), but let me call the reader's attention to the fact that while after a definite noun there appears another definite article before the adjective in Hebrew ( $h \bar{a}$-' $\hat{\imath} \hat{s}$ hag-gādôl the-man the-great i.e. 'the great man'), after an indefinite noun the article (or determinative pronoun) is absent before the adjective, too ('îš gâdôl man great i.e. 'a great man'). In my opinion this phenomenon can be explained as an agreement in definiteness, and it is far from being similar to the Coptic adjective particle whose appearance is indifferent to the definiteness of its noun, as it can be seen in (17b). (17a) would not be grammatical with an indefinite article. (17c) pro- 


\section{Barbara Egedi}

vides a clearer case where the presence of the possessive article evidently excludes the genitive interpretation of the adjective linking particle.

Perhaps this ambiguous status is responsible for the fact that some Coptic grammars refer to both ${ }^{e} n$ - morphemes with the same rather neutral names as mark of relationship (Layton 2000: \$203) or nota relationis (ShishaHalevy 1986: 20). I prefer calling it a genitive particle (cf. Till 1986: §113: "Genitivpartikel") or rather marker, thus indicating that it functions as a case-marker or much alike.

It is worth mentioning that the notion of "case" in Coptic does not go without saying. The only obvious structural case is the nominative (for its position see Reintges 2001: 100). The object of the verb can be expressed either by a prepositional phrase or by forming a construct state with the verb. The latter is a procedure, which is not a possible in every conjugation type. Apart from these cases all of the relations within the sentence are expressed by prepositions. That is why the case-marker status of the ${ }^{e} n_{-}$ morpheme is not self-evident for me.

The ${ }^{e} n t e-,{ }^{e} n t a-$ of pattern B is a better candidate for being a preposition: it has two allomorphs, the first of which was exemplified in (11)-(13). The second form serves for introducing pronominal possessors.

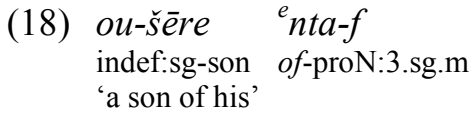

This view is shared by many authors (Till 1986: $§ 113$; Lambdin 1983). Nevertheless, Layton (2000: §204) finds it questionable, arguing that it never modifies a preceding verb or verbal clause. On the one hand there is no doubt about its prepositional origin (Loprieno 1995: 71), on the other the above criterion does not seem to be relevant in defining the preposition as a category.

In the Coptic data, there is an well-observable complementary distribution between the two patterns. Although earlier grammars pointed out the syntactic conditions of this distribution, Layton explains it on semantic grounds. He speaks about a restrictive expansion, a construction of two entity terms such that one restricts the meaning of the other by limiting the number of referents to which it applies (Layton 2000: §146). In his terminology, restrictive expansion has two types: the general (possessive) relationship and the appurtenance construction, but they do not correspond exactly to our pattern A and pattern B division. Shisha-Halevy argues that the original opposition was essential possession vs. incidental possession or 
appurtenance but it is usually neutralised and maintained in isolated cases only (Shisha-Halevy 1986: 21). I maintain that the factors determining the choice between them are purely syntactic: the choice depends on what kind of other NP modifiers are present. In 3.2.3., it has been shown that pattern A is used with simple definite possessions only, while pattern B appears practically in every other case.

As a matter of fact, the distribution seems unusual at first sight, but we find a similar phenomenon in the English preposed/postposed genitive alternation. The preposed possessive construction (John's book, a teacher's work) is always understood as definite. Lyons explains it by the fact that the genitive phrase is in Det position, and the filling of this position forces a definite interpretation (Lyons 1986: 138-140). In the case of an indefinite head noun, another construction has to be used (a friend of mine), typically a PP complement. This PP construction occurs when the head $\mathrm{N}$ is modified by a demonstrative (this friend of mine). As a general rule, it is available to make possible anything other than a simple definite possessive, which is all the preposed construction can express. ${ }^{14}$

The resemblance (of the English constructions) to the distribution of Coptic genitive constructions is striking. Though Coptic has no preposed constructions (except with a pronominal possessor), pattern A implies the same simple definite interpretation. While in English the preposed genitive and the definite article cannot co-occur (*the John's book) - presumably because they occupy the same structural position, ${ }^{15}$ the Coptic genitive phrase in pattern $\mathrm{A}$ is in a postposed position, and the noun phrase has an overt definite article.

I claim that there is a correlation between the English and Coptic data, and in the next section I intend to provide an adequate account of this fact and determine the exact structure of Coptic possessive patterns.

\section{The structure}

\subsection{A modified checking theory}

In 2.2. we have asserted that for being checked, formal features must be in some local structural relation and it is this requirement that motivates movement. First, Chomsky (1993) formulated the principle of Greed: Move $\alpha$ applies to an element $\alpha$ only if morphological properties of $\alpha$ itself are not otherwise satisfied. In other words, movement is triggered by the mor- 


\section{Barbara Egedi}

phological requirements of the moved element. Lasnik (1999) suggests a revision of Greed in terms of Enlightened Self Interest (ESI): The morphological requirement can be either one of the moving element (as with Greed) or one of the position it is moving to.

At the same time Chomsky (1995) modifies his principle apparently to the contrary, his "Suicidal Greed" insists that only the target is relevant: Movement happens only when a category with an uninterpretable feature attracts some feature into its checking domain. (cf. The principle Attract: Chomsky 1995: 297)

Carstens giving a version of Lasnik's ESI replaces Chomsky's Attract with the principle Move (Carstens 2000: 324), which essentially suggests the same: the features of the target have no special status in the motivation of movement; if a category has uninterpretable features, it may either raise itself or "attract" raising for checking purposes. The features may be "strong", requiring immediate checking via overt movement, or "weak", in which case checking takes place only in covert syntax - obeying the economy principle of Procrastinate.

This extended version of the checking theory will fit our analysis of genitive constructions, but first of all I intend to show the base structure of the simple noun phrase in Coptic.

\subsection{NP without possession}

The bare noun $[\mathrm{NP}[\mathrm{N}$ rōme] $]$ without any determiner is underspecified for number and in cross-reference it can be either plural or singular (Layton 2000: §48). Meanwhile gender must be an intrinsic feature of nouns, testified by adjectives agreeing with it. Adopting the idea that there is a functional projection NumP above the lexical NP, I consider the Num head to be responsible for number specification.

As the noun precedes the genitive expression and the adjectives ${ }^{16}$ in the word order, we can assume that $\mathrm{Num}^{\circ}$ has a strong category feature for $\mathrm{N}^{\circ}$, hence $\mathrm{N}$ overtly raises and adjoins to it. 


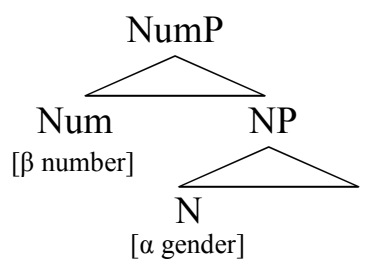

(20)

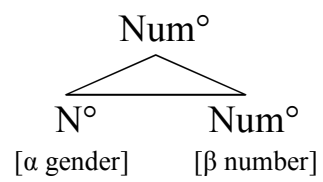

Overt movement is supported by 'irregular' morphological plural forms, ${ }^{17}$ where formal features are visible on nouns (21), hence the morphological requirement of movement is obvious. It is interesting to observe that adjectives, which - in my opinion - normally do not leave the NP projection, may have exceptional plural forms, but these forms occur mainly in nominalized usage (22).
(21) ${ }^{e} n$-snēy $\quad{ }^{e} n-s a b e^{18}$ def:pl.-brother:pl wise 'the wise brothers'
(22) ${ }^{e} n$-sabeeye ${ }^{19}$ def:pl.-wise.pl 'the wise (men)'

The indefinite articles (see the forms in (5)) are merged probably in Spec,NP, but they have to check their uninterpretable number features, hence they raise to the specifier of NumP, where they are in appropriate spec-head checking relation with the $\mathrm{N}+\mathrm{Num}$ head.

The definite articles are heads of the DP determiner phrase or more precisely - adopting Lyons's theory (1999) - of the definiteness phrase. As we could see in (2), the Coptic definite article shows agreement in gender and number features with the noun. As a matter of fact, agreement (i.e. concord) takes place between $\mathrm{D}^{\circ}$ whose uninterpretable gender and number features motivate raising to check them, and the features of $\mathrm{N}+\mathrm{Num}$ head. The raising of features takes place in covert syntax as no overt movement can be observed. $^{20}$ 
(23)

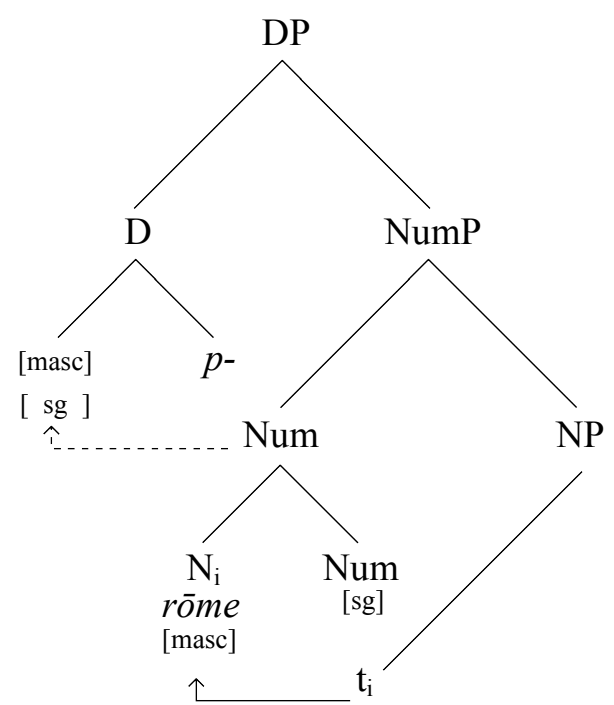

Demonstratives (see (3)) seem to have a [definite] feature. Identifiability is somehow part of their semantic content, so demonstratives always imply definiteness (Lyons 1999: 18-21). For this reason, they appear in $\mathrm{D}^{\circ}$ like the definite article, and this is why they - demonstratives and definite articles can never co-occur in the same phrase.

Demonstratives can check their uninterpretable gender and number features in the same manner as the articles: the corresponding features of the $\mathrm{N}+\mathrm{Num}$ head are attracted to check them.

\subsection{Genitive constructions: pattern A}

The pattern A exemplified in (10) provides a real challenge for our investigation. We have to face several questions: what happens during the derivation ensuring that the possessed noun always be definite and at the same time excluding any other determiner from the phrase? Where is the genitive phrase base-generated?

Derived (deverbal) nouns (especially those expressing a process or an event) inherit the theta-grid of the verb. The arguments of the noun should be generated in the corresponding external/internal argument positions. (Ritter 1991; Siloni 1996). For example, the agent argument is assigned nominative case in verbal constructions and genitive case in nominal con- 
structions. The theme argument is assigned accusative case in both constructions. This is the case in Hebrew (26) and in Coptic, as well: ${ }^{21}$

(24)

p-ei ebol $\quad{ }^{e} m$-p-israēl $h^{e} n$-kēme $e^{22}$

the-come:inf. forth of-the-Israel from-Egypt

'the-coming forth of-the-Israel from-Egypt'

(25a) $p$-koos- $t^{23}$

the-bury:inf.-1.sg.

'my burial (the burying-me)'

(25b) *pa-kōoss

poss.art.-bury:inf 'my burial'

(26) axilat dan et ha-tapuax (Hebrew) ${ }^{24}$

eating Dan acc.the-apple

'Dan's eating of the apple'

If we suppose that the base position of the phrase expressing the possessor is in the SpecNP, the combination of a genitive construction with an adjectival modifier (possibly adjoined to $\mathrm{NP}^{25}$ ) would yield the Possession + Adj(s) + Possessor order:

(27a) *p-šēre ${ }^{e} n$-cabe ${ }^{e} m$-p-rōme def:sg.m-son clever of-def:sg.m-man 'the man's clever son'

(27b)

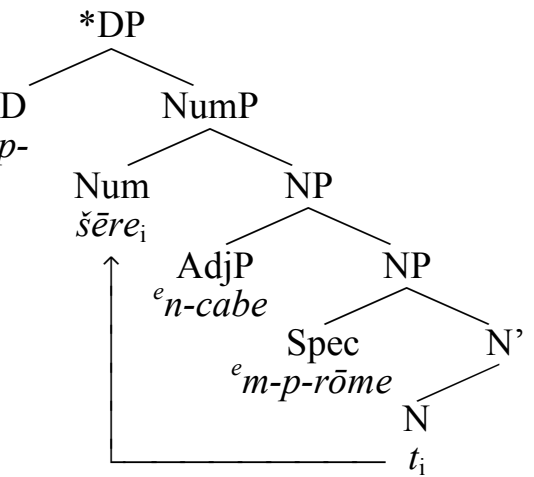

However, in Coptic the possession and the possessor require direct adjacency in pattern A, therefore adjectives must follow both of them (which otherwise results in structural ambiguity, since the adjective may be the modifier of either of the nouns): 
(28) p-šère ${ }^{e} m$-p-rōme ${ }^{e} n$-cabe

def:sg.m-son of-def:sg.m-man clever

a) 'the man's clever son'

b) 'the clever man's son'

To ensure the direct adjacency and the licensing of genitive case we have to assume a PossP projection with an abstract possessive morpheme ${ }^{26}$ in its head, and with the possessor phrase in its specifier. It would explain the exceptional behaviour of the genitive marker ${ }^{e} n$-, ${ }^{e} m$-, and it can be regarded as a case marker on the possessor.

But we have not given account of the fact that the head noun in pattern A cannot be indefinite or modified. It seems reasonable to assume that the possessor phrase works as a determinant, it has a [definite] feature. There is a similar assumption for Hungarian caseless possessor phrases, which are claimed to have a [determininer] feature and move to DP domain to have it checked. $^{27}$

In Coptic, the possessor itself does not raise. Its [def] feature is weak, and there is no overt movement - as it is attested in Hungarian or English (a boy's book). Nevertheless, the [definite] feature of the possessor has to be raised in order to be checked by the $\mathrm{D}$ head. The definite article - as a default determiner - seems to be the phonological realization of the [def] feature in the DP, otherwise lacking lexical content. As a consequence, the presence of the definite article excludes the demonstrative and the possessive article to occur in the same structure.

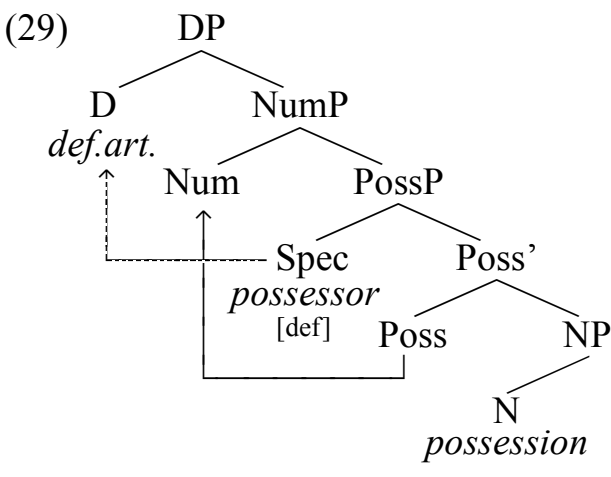

The uninterpretable gender and number features of the definite article will be checked as illustrated in (23).

Returning to the original assumption that the possessor phrase originates in Spec,NP we could also exclude the appearance of an indefinite possession 
in pattern A. I supposed earlier that Spec,NP is the starting-point also for the indefinite articles, so the indefinite noun and the possessor of type A mutually exclude each other. However, the possessor merged in Spec,NP has a further [gen] case feature (beside his [def] feature), which can be checked in Spec,PossP. The possessor phrase is raised to the PossP domain overtly, the proof of which is given by the possession-possessor-modifier(s) word order discussed above (see (27) and (28)).

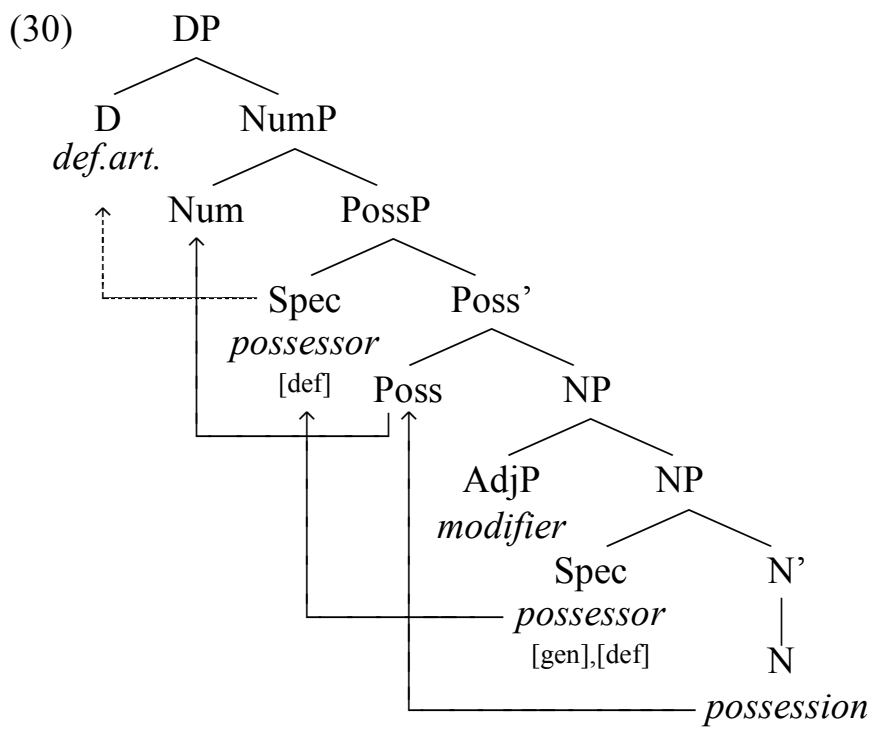

The possessive article which encodes the pronominal possessor has an interpretable [definite] feature (see (4) and (14)) and its derivation is parallel in manner with that of demonstratives. They are in the D-head and combine with the NP by merge.

However, the definite feature assignment to the possessor is not so selfevident if we take into consideration languages classified as adjectivalgenitive by Lyons (1999). From (31) it can be seen, that in Italian the pronominal possessor can co-occur with a definite/indefinite article.

(31a) il mio amico the my friend (31b) un mio amico

a my friend

Two conclusions can be drawn from (31): the pronominal possessor does not occupy the $\mathrm{D}^{\circ}$ position since it seems to be reserved for the definite 


\section{Barbara Egedi}

article $i l$, moreover, the possessiveness itself does not involve definiteness as a rule. However, this divergence can be due to parametric variation among languages.

\subsection{Genitive constructions: pattern B}

As it was stated earlier, pattern B constructions appear with indefinites, demonstratives, and other modifiers in the noun phrase, as it was exemplified in (11)-(13). The possession-possessor sequence can be interrupted by certain elements in the phrase, but their relative order is retained.

An exception to this constraint could be the predication of possession, a special grammaticalised structure in Coptic. Existence or non-existence are predicated by oun "there is" and $m^{e} n$ "there is not", respectively, followed by the subject, indefinite ${ }^{28}$ as it can be expected. Their combinations with the preposition ${ }^{e} n t e-,{ }^{e} n t a-$ yields the combinations ounte-, ounta-; $m^{e} n t e-$, $m^{e}$ nta- expressing possession and its negation respectively (Till 1986: $\S \S 289-294$; Lambdin 1986: 90-91; Layton 2000: $\S 383-390)$. In these constructions the ${ }^{e} n t e$ - phrase seems to move out from its postposed position, but the occasional appearance of the object-marker on the possession (32) suggests that the ounte- combination has been reinterpreted as a verb, and the original subject has become the object of the compound verb denoting "have" (Polotsky 1987: §40). So this pattern is no more suitable for a target of our investigation.

(32) ou iente-p-rōme (n-)ou-shime

have-def:m.sg.-man (obj.)-indef:sg.-wife

'the man has a wife'

Returning to genitive constructions, we can state that the ${ }^{e}$ nte-phrase follows the possession, although it can be separated even by a short embedded relative clause (33).

(33)

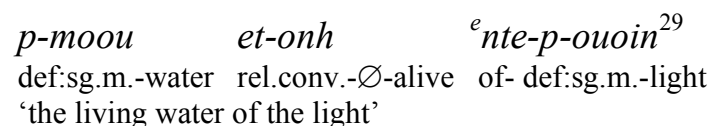

Moreover, it can leave the noun phrase domain:

(34) ere $h^{e}{ }^{e}{ }^{e} n k a$ čalōou ero-f ${ }^{e}$ nte-ou-rōme $e^{30}$ foc. indef:pl.-thing entrust:stative to-3.sg.m of-indef:sg.-man 'someone's things were entrusted to him' 
This mobile character of the possessive in pattern B and the prepositional nature of ${ }^{e}$ nte- discussed in 3.2.3. indicate that this genitive cannot be a structural case. Anyway, it does not have any kind of [def] feature, so it cannot be generated in the same position as pattern A. The genitive case seems to be an inherent one, licensed by the preposition ${ }^{e}$ nte-.

For a similar phenomenon, namely the Hebrew postnominal šel-phrase (an alternative genitive construction beside the so-called Construct State), Ritter suggested that it should be a base generated adjunct attached to the matrix DP. ${ }^{31}$ Providing a similar derivation for Coptic, the phrase could adjoin either to NumP or to DP - or in exceptional cases to CP, as well (34).

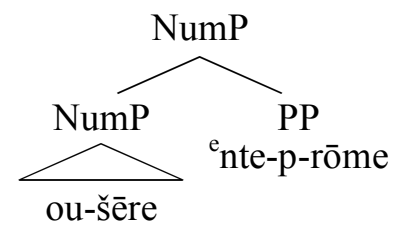

$(35 b)$

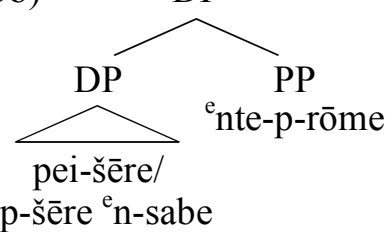

An alternative analysis could be that the ${ }^{e}$ nte- phrase is directly adjoined to NP, similarly to the adjective-adjunction. However, as we have seen, adjectives modifying the same head noun precede the ${ }^{e} n t e$ - possessor in linear order (see (12)). What kind of constraint should be introduced into our syntax to ensure the proper order? $?^{32}$

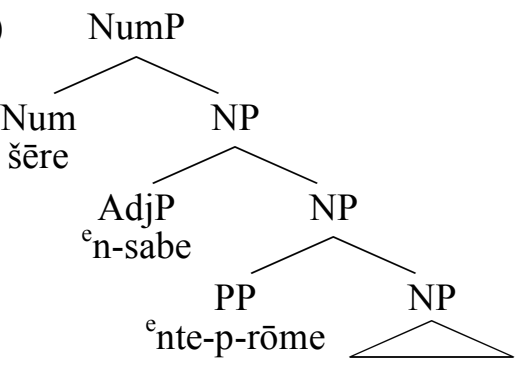

For lack of such a constraint the former adjunction-hypothesis seems more plausible.

The last question that remained is that if the ${ }^{e} n t e$ - phrase can be adjoined to a DP as well, what prevents it from appearing with the simple definite possession. Provided that the above derivations are right, the preference for pattern A seems to be due to economy conditions only. 


\section{Conclusion}

In this paper I intended to provide an account of the basic nominal constructions in Coptic with special attention to the two different genitive structures, which I called pattern A and pattern B. The former had restrictions in respect of the definiteness of the head noun, and I suggested an analysis according to which the definite feature of the possessor checked in the covert syntax assures these restrictions to be satisfied. The latter construction is a looser relation between the possession and the possessor, and several facts indicate that basically it has a different structure, probably an adjunction on distinct levels of the noun phrase.

Many questions remained open regarding the Coptic noun phrase structure which I have not even attempted to answer for the moment. The systematic investigation of the adjectives and their relative order within the noun phrase may reveal new results not only for Coptic studies but for the Universal Grammar, as well. It may also modify the issue of the present paper, and I hope to continue an instructive inquiry - for the linguistics of dead languages, too.

\section{Acknowledgements}

For helpful comments and suggestions on an earlier version of this paper I owe thanks to Huba Bartos, Katalin É. Kiss and Chris H. Reintges. I am also grateful to Zsuzsa Kertész for correcting my English. All errors are, of course, my own.

\section{Notes}

1. e. g. rules like the pronunciation of the ou sequence that has two values: a consonantal $[\mathrm{v}]$ and a vocal $[\mathrm{u}]$ depending on its position within a syllable. The transcription is based on Lambdin (1983: x.) I initiated only one more diacritic sign: ${ }^{\mathrm{e}}$ which corresponds to the Coptic supralinear stroke. It was used to indicate either a syllabic consonant or a short schwa before the letter in question. The abbreviations used for grammatical expressions: acc. = accusative; circ. $=$ circumstantial; conv. $=$ converter; def. $=$ definite; dem. $=$ demonstrative article; foc. $=$ focus-marker; gen. $=$ genitive; indef. $=$ indefinite; poss. $=$ possessive article; proN $=$ pronoun; prt. $=$ particle; ps. $=$ present; rel. $=$ relative. 
2. Szabolcsi argues for an INFL node in Hungarian noun phrase as early as in 1981, claiming that NPs have a sentence-like structure with agreement features.

3. "if there is a leading technical idea in Minimalism, it is that movement is a last resort, taking place only when triggered by a driving force" (Lasnik 1999: 2.)

4. As Huba Bartos pointed out to me (pers. comm.) concord is an "internal" correlation between potentially more than two items - sharing in a feature that is a property of the whole category containing them, unlike in the case of sentencelevel agreements, where we always find "external" correlation between two items. So the comparison of concord and agreement raises some theoretical problems.

5. The nucleus of the article phrase is the article itself, expressing grammatical and referential information, the expansion element expresses lexical content. (Layton 2000: §43) He treats indefinite and definite determiners in the same way, without making the obvious distinction, otherwise relevant in syntax, between them. In an earlier study he speaks about "determinator syntagm" (Layton 1990).

6. In the examples below the $-f$ element in pef- is a 3. sg. m. marker.

7. Converter is the traditional name for a group of Coptic complementisers. The two converters in (8) and (9) show some syntactic difference: after the circumstantial converter a resumptive pronoun always has to be present in subject position, while in the case of the relative clause - in well definable conditions a null-form can be attested.

8. The variant em- is the result of a simple phonological rule, namely, that before bilabial stops ( $\mathrm{p}, \mathrm{m}) n$ becomes $m$, and on certain morpheme boundaries this assimilation was reflected in the spelling.

9. Shisha-Halevy seems sceptical whether demonstrative-modified nouns fall under this case. Opinions vary in this respect.

10. Prepositions in Coptic have two distinct forms depending on the category (noun vs. clitic-like personal pronoun) of the following complement. This fact will be relevant when arguing that the $n$ - introducing the possessor phrase is not a preposition.

11. But in that case it behaves like a preposition having two forms, one for prenominal and one for prepronominal use.

12. All of them from the same text (The Life of Apa Onnophrios, Till, 1986: 282)

13. Attributive constructions show certain variation, the discussion of which does not concern us here. See Layton $(2000, \S \S 96-103)$

14. Lyons $(1986,140)$ Lyons introduces a new distinctions: languages of the above type are determiner-genitive (DG) languages, while languages like Italian, where genitives can co-occur with the definite and also with the indefinite article (il mio libro, un mio libro) are adjectival-genitive (AG) languages. For further details: Lyons (1986 and 1999, Ch. 8.)

15. More precisely, the genitive is in SpecDP and the article in $\mathrm{D}^{\circ}$, but only one of the two positions can be filled within the phrase. 


\section{Barbara Egedi}

16. Adjectives can precede their nouns but its conditions and problems do not concern us here. I suppose for now that $\mathrm{N}$ Adj sequence is the unmarked one.

17. About one hundred nouns have a distinct plural form as well (according to Layton to express the category of individual concrete plurality, Layton 2000: $\S 108 b)$.

18. From son 'brother' in singular

19. From sabe 'wise' in singular (Lambdin 1983: 58)

20. This analysis follows that of the Italian determiner $l e$ in Carstens (2000: 329)

21. In reality, Coptic uses the infinitive form of the verb in both constructions. An alternative analysis for DPs supposes an $\mathrm{nP}$ "shell" above the core NP - following VP-shell hypothesis - and its specifier provides the position where the possessor or the agent of derived nouns can be generated. (Carstens 2000; Radford 2000). This analysis seems to be redundant for Coptic because of the above-mentioned infinitival character of the nominal constructions. One hardly finds any deverbal derived noun with its full argument structure.

22. Ps 113(114): 1. (Lambdin 2000: §105)

23. Matt 26:12. (Lambdin 2000: §105) The personal pronoun is in canonical object position. Its realization is clearly different from that of pronominal possessors of simple nouns lacking arguments. (25b) would be grammatical only with this latter type.

24. Ritter 1991, 39 (2b)

25. There is a general uncertainty concerning the generation of adjectives: are they adjunctions or generated in SpecXP? For the moment I accept the common assumption that they are adjoined to a maximal projection. About this problem and a different point of view: Cinque (1995)

26. Radford (2000); this view is supported by the fact that in Hungarian (and in Turkish) there is a visible agreement inflection on the possessed noun. Cf. É. Kiss (2000)

27. É. Kiss (2000: 134). The Hungarian noun phrase has a relatively complex structure with real agreeing properties in genitive constructions. Its demonstration would need a more detailed analysis than it seems relevant to our understanding of Coptic NPs. Beyond a desultory comparison, there seem to be more differences than similarities between the constructions of the two languages. (For references, see: Szabolcsi 1994; É. Kiss 2000, 2002: Ch. 7. among others.)

28. Polotsky (1960: §33) exhaustively enumerates the possible subject types, but practically these cases are all indefinite.

29. From p.Beroliensis 8502, 26, 20. after Till 1986, §113

30. After Reintges $(2002,350$. (9))

31. And it freely receives a default possessor interpretation. Ritter 1988, 921. In Ritter (1991) she modifies her theory, and supposes two sources of šel: either a realization of case assigned by $\mathrm{N}$ to an argument inside NP or the head of a DP adjunct. (Ritter 1991: 48) The Coptic ${ }^{e}$ nte-phrase does not seem to appear for expressing an argument of the infinitival nominal constructions. 
32. In the theory of Cinque (1995) every adjective and attributive modifier in the phrase has its own projection with the adjectives in the specifier position and these projections can be ordered hierarchically. If there were also a so-called ${ }^{e}$ nte-projection, it could be positioned directly over the NP.

\section{References}

Abney, Steven

1987 The English noun phrase and its sentential aspect. Ph. D. diss., Cambridge, Mass.: MIT.

Bernstein, Judy

1991 DPs in French and Walloon: evidence for parametric variation in nominal head movement. Probus 3.2: 101-126.

Carstens, Vicki

2000 Concord in Minimalist Theory. Linguistic Inquiry 31: 319-355

Chomsky, Noam

1993 A minimalist program for linguistic theory. In The Minimalist Program, 1995, Noam Chomsky, 167-217. Cambridge, MA: MIT Press.

1995 Categories and transformations. In The Minimalist Program, 1995, Noam Chomsky, 219-394. Cambridge, MA: MIT Press.

Cinque, Guglielmo

1995 On the evidence for partial N-movement in the Romance DP. In Italian Syntax and Universal Grammar, Guglielmo Cinque (ed.), 287309. Cambridge: Cambridge University Press.

É. Kiss, Katalin

2000 The Hungarian noun phrase is like the English noun phrase. In Papers from the Pécs Conference, Approaches to Hungarian 7, Alberti Gábor and Kenesei István (eds.), 121-149. Szeged: JATE Press.

2002 Hungarian Syntax. Cambridge: Cambridge University Press.

Giorgi, Alessandra and Giuseppe Longobardi

1991 The Syntax of Noun Phrases: Configuration, Prameters, and Empty Categories. Cambridge: Cambridge University Press.

Grimshaw, J.

1991 Extended projection. Ms., Brandeis University.

Lambdin, Thomas O.

1983 Introduction to Sahidic Coptic. Macon: Mercer University Press.

Lasnik, Howard

1999 Minimalist Analysis. Oxford: Blackwell.

Layton, Bentley

1990 The Coptic Determinator Syntagm and its Constituents. Journal of Coptic Studies 1: 79-97. 
Layton, Bentley

2000 A Coptic Grammar with Chrestomathy and Glossary. Sahidic Dialect. Wiesbaden: Harrassowitz Verlag.

Loprieno, Antonio

1995 Ancient Egyptian. A Linguistic Introduction. Cambridge: Cambridge University Press.

Lyons, Christopher

1986 The syntax of English genitive constructions. Journal of Linguistics 22: $123-143$.

1999 Definiteness. Cambridge: Cambridge University Press .

Polotsky, Hans Jacob

1960 The Coptic conjugation system. Orientalia 29: 392-422 .

1987 Grundlagen des koptischen Satzbaus. Erste Hälfte. American Studies in Papyrology 28. Decatur, GA: Scholars Press.

Radford, Andrew

2000 NP shells. Essex Research Reports in Linguistics 33: 2-20.

Reintges, Chris H.

2001 Agreement marking, case assignment and the composition of the Coptic clause. Göttinger Miszellen 180: 97-102.

2002 A configurational approach to Coptic second tenses. Lingua Aegyptia 10: $343-388$.

Ritter, Elisabeth

1988 A head-movement approach to construct-state noun phrases. Linguistics 26: 909-929.

1991 Two functional categories in noun phrases: Evidence from modern Hebrew. In Perspectives on phrase structure: heads and licensing, Susan Rothstein (ed.), 37-62. (Syntax and semantics 25.) San Diego: Academic Press.

Shisha-Halevy, Ariel

1986 Coptic Grammatical Categories. Structural Studies in the Syntax of Shenoutean Sahidic. (Analecta Orientalia 53.) Roma: Pontificium Institutum Biblicum.

Siloni, Tal

1991 Noun raising and the structure of NPs. MIT Working Papers in Linguistics 14: 255-270.

1996 Hebrew noun phrases. In Parameters and Functional Heads: Essays in Comparative Syntax, Belletti, Adriana and Luigi Rizzi (eds.), 239-267. Oxford University Press. 
Szabolcsi, Anna

1981 The possessive construction in Hungarian: a configurational category in a non-configurational language. Acta Linguistica Academiae Scientiarum Hungaricae 31: 261-289.

1994 The noun phrase. In The Syntactic Structure of Hungarian. Kiefer, Ferenc and É. Kiss Katalin (eds.), 179-274. (Syntax and Semantics 27.) San Diego: Academic Press.

Till, Walter C.

1986 Reprint. Koptische Grammatik (Saïdischer Dialekt). 2. Aufl. 1961. Leipzig: VEB Enzyklopädie Verlag.

Vergote, J.

1950 La phrase nominale en copte. In Coptic Studies in Honor of Walter Ewing Crum, 229-242. (The Bulletin of the Byzantine Institute 2.). Boston: The Byzantine Institute. 
